\title{
Choice criteria of personnel selection methods
}

\author{
Case of SME in St. Petersburg
}

\author{
Vladimir Andreevich Kadnikov \\ Institute of Management, Economics and Finance \\ Kazan Federal University \\ Kazan, Russia
}

\author{
Alexandra Dmitrievna Kosintseva \\ Graduate School of Management \\ Saint Petersburg State University \\ Saint Petersburg, Russia
}

\begin{abstract}
This study investigates the staff selection process and identifies particular criteria influencing the personnel selection methods. Such methods of personnel selection as screening, interview, questionnaire, lie detector, biographical method, assessment center and reference checks are analyzed. This empirical research is based on a sample of $\mathbf{4 0}$ companies of different business areas from St. Petersburg, Russia. The authors use regression models for testing several hypothesis regarding the relation between selection methods and the factors such as company's size, age, business area, job complexity or the number of required skills, and the amount of required training. The authors found that the more skills are required for a job position, the higher the degree of use of personnel selection methods by the companies. Moreover, the authors observe that business area influence the degree of use of selection methods. In particular, construction companies use phone interviews more intensive than companies of other business areas do. Financial companies use lie detector more frequently than others do; manufacturing companies - biographical methods and reference checks. Finally, large companies use more phone interviews, personality test, questionnaire and lie detector compared to small companies. At the same time, authors did not reveal the relation between length of formal adaptation period and the degree of use of personnel selection methods.
\end{abstract}

Keywords- personnel, hiring process, selection methods, choice criteria

\section{INTRODUCTION}

This study investigates the staff selection procedure employed by companies in St. Petersburg. The relevance of this study stems from the fact that existing studies of HR, particularly recruitment, are mostly focused on large corporations. In this regard, there is a lack of information about selection methods, adequate for small and medium business [1-3]. In addition, many authors, describing various recruiting procedures, note that, in practice, a specific, often small, set of methods is used [4]. Existence of different selection methods crates a problem of choosing the most effective methods.

Some studies of recruitment process indicate a more frequent use of the selection methods, which are less valid than other methods [5]. So far, there is insufficient knowledge about the reasons for the choice of personnel selection methods and the lack of studies of the choice of selection methods and factors influencing that choice [6].
One of the most important factors influencing the general strategy of selection and particular selection methods is the HR strategy of the company, which in turn should comply with the business strategy $[7,8]$. Other factors influencing the choice of selection methods are described in studies of decision-making process $[9,10]$.

The goal of this study is to investigate the influence of job characteristics and organizational features on the choice of personnel selection methods and to identify the most frequent methods of personnel selection in companies of St. Petersburg, Russia.

\section{MODERN PERSONNEL SELECTION METHODS}

Let us define selection as a part of hiring process, in particular - analysis of job requirements and choice of high potential candidates. The authors give a brief description of the main selection methods, which degree of use is analyzed in this study.

\section{A. Screening}

Screening is the primary review of candidates with the aim to limit the number of candidates for further detailed review. Several varieties of screening exist: screening based on resumes and profiles of candidates, phone screening and biographical screening. In this study, resume screening is exclusively analyzed.

\section{B. Telephone interview}

This method essentially is a kind of screening. The allocation of a telephone interview in a separate method is subjective: a telephone interview is a potential mean of candidate rejection just after screening. Some researchers believe that telephone interviews are harder to prepare for, and therefore the information obtained during the interview is more reliable [4].

\section{Questionnaire}

This may be an outdated selection method, which, together with forms of biographical information, evolved in the candidate's resume. The extended questionnaire is often used in two cases: in the absence of the candidate resume and in case of hiring people from other companies other than promoting own staff. In both cases, the questionnaire is used for low qualification positions. Typically, such questionnaire contains a set of questions of general, personal, social, biographical and other subjects [4]. 


\section{Personal interview}

This method is the most common and the most important in the decision-making process about the choice of the candidate. Generally, interviews can by classified by number of interviewers (group or individual) and by the level of structure (unstructured, semi-structured and structured). The popularity of the interview method is partly a consequence of its deceptive simplicity [11]. Regarding group interviews, it is becoming more and more popular to have interview with 2 interviewers, one of which is an HR specialist and another one is a specialist from the business department [12].

There is a difference between simple and competencybased interviews. A competency-based interview is a type of an interview intended to disclose the main characteristics of the personality according to the established competence profile of a position [14]. The use of the competency model suggests ways to assess competences through a specific set of behavior indicators [15]. Usually, competence approach in the companies is presented solely by competency-based interviews.

\section{E. Selection tests}

Generally, selection tests are divided into 2 groups:

1. Aptitude tests

$$
\begin{aligned}
& \text { a. Performance tests } \\
& \text { b. Intelligence tests }
\end{aligned}
$$

\section{Personality tests}

In this study, by selection tests the authors mean a test from any of groups mentioned above.

\section{F. Biographical method}

The biographical method involves the analysis of the past of the candidate based on established criteria. The source of biographical data under this method should be a more detailed document than the resume of the candidate - a biographical questionnaire. The candidate is selected only if both his profile and the forecast of his future behavior comply with established criteria. Selection criteria are established using the analysis of a position and a set of required competencies [20].

\section{G. Lie detector test}

This is a rare, unconventional method, the use of which is complicated by its pseudo-scientific nature and the lack of legal framework. The lie detector test used to be a frequent selection method in the USA to check property accountability of employees [25].

\section{H. Assessment center}

An assessment center is a process, which includes a set of methods and several observers and the aim of which is to identify the suitability of the candidate for a job position [5]. In this study, business games and role plays are considered as the base of the assessment center.

\section{References checks}

References check involves confirmation of the existing and obtaining additional information about the candidate via the sources listed in the candidate's resume or obtained by any other way. Several authors mention that most managers prefer to request for references by phone as the fastest and most reliable way [4], [11].

\section{CHOICE CRITERIA OF PERSONNEL SELECTION METHODS}

Choice criteria of methods of personnel selection are features of the environment of the organization, which, ceteris paribus, affect the choice of methods of personnel selection in the company. In general, researchers agree on the variety of factors influencing the choice of methods and the complexity of evaluating their effectiveness in each case [4]. Some authors write about the necessity of economic justification of methods of selection and the selection rate as well as indicators of compliance of the perspective and actual results. [16].

Publications in the field of choice criteria of methods of personnel selection are not numerous, but still one may conclude that all choice criteria are divided into 3 groups by the level of organization: company's environment-based criteria, company-based criteria and job-based criteria. These groups are shown in the chart below.

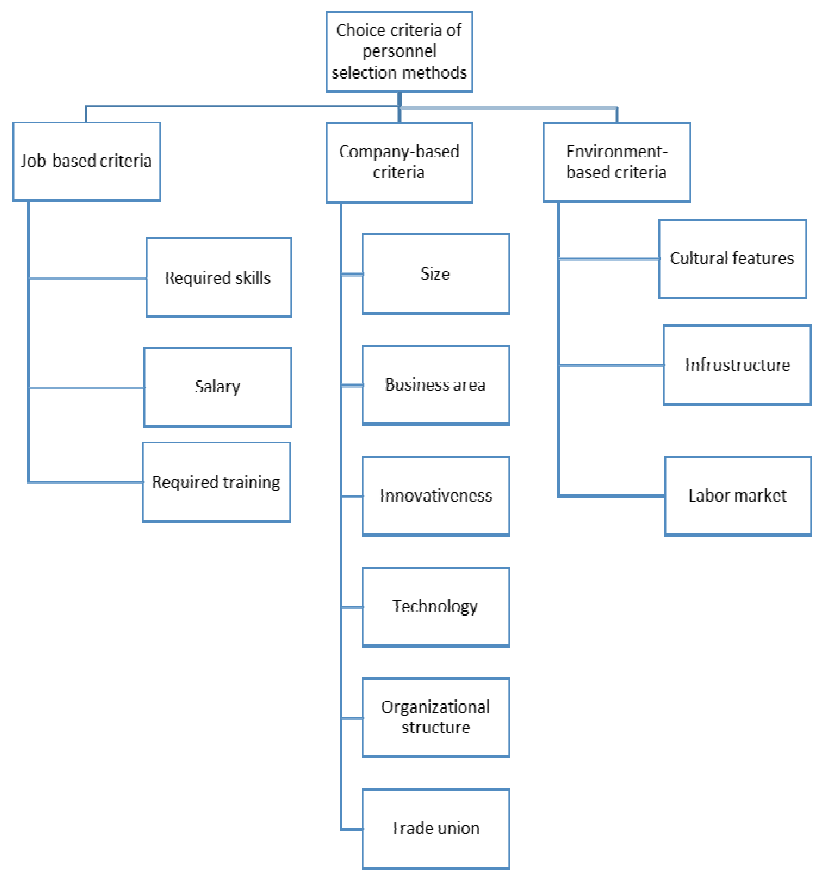

Fig. 1. Choice criteria of personnel selection methods

These theoretical materials are useful for nomination and verification of hypotheses later in this paper as well as for a deeper understanding of the choice criteria of methods of personnel selection

\section{DEGREE OF USE OF SELECTION METHODS}

Let us assume that companies increase the degree of use of selection methods in order to increase the accuracy of selection. In the studies devoted to the methods of selection, such degree of use is most commonly expressed through the frequency of methods' application. Generally, frequency is 
measured by HR specialists themselves: they are asked to estimate the frequency of use of selection methods on a scale of 1-5 where 5 means that the method is always used, $3-$ sometimes, and 1 - never. The authors believe that this indicator is not reliable for estimation of the company's intention to increase the accuracy of selection. There can be any method with the greatest degree of use in such context, even the simplest and fastest method. For example, resume screening is used for job position of all levels and this method indeed improves the accuracy of selection compared to random selection of candidates' resumes.

However, it should be noted that the use of more complex and time-consuming methods is a better sign to demonstrate the company's intention to increase the accuracy of selection. The authors argue that the degree of use of a particular selection method must reflect both the average time spent on a selection method and the frequency of its use. Thus, the degree of use of all selection methods in the company (DUSM) is determined as the sum of the products of the frequency of use and average time spent on each selection method. Let us use DUST as a dependent variable in this empirical study, the methodology and results of which are described further in this paper.

\section{HYPOTHESES OF THE STUDY}

Below let us state and describe several hypothesis of the research.

\section{H1: The degree of use of selection methods depends on} the number of required skills

The number of required skills for a particular job position is a proxy for the complexity of the work. It will be determined by such indicator as a job seniority level. Let us assume that all job positions can be divided into 3 groups by the level of work complexity. The higher the seniority level of a job position, the greater the number of required skills.

H2: Degree of use of selection methods has an inverse relation with the amount of required input training

This hypothesis follows the assumption that the higher degree of use of selection methods leads to a more accurate selection. A more accurate selection, ceteris paribus, means that less training is needed. The indicator of training volume will be the average duration of training, accepted for a job position. Training implies not an organized formal educational process but an adaptation period and mentoring by more senior colleagues. Generally, corporate training is available only in large companies; thus, the selected indicator is justified [17].

H3: Degree of use of selection methods depends on business area of a company

Obviously, companies of different business areas use selection methods differently, so the hypothesis probably will be confirmed. The authors are interested in detecting the business areas, the companies of which have the highest degree of use of personnel selection methods.

H4: Degree of use of selection methods depends on the size of a company
International study of Ryan A.M. had an aim to measure the influence of national and cultural features on the differences in personnel selection methods. That study revealed several differences for large and small companies: large companies tend to use interview more frequently but references check less frequently that small companies do [18]. Thus, let us generate 2 sub-hypotheses:

H4a: Degree of use of interview depends on the size of a company

H4b: Degree of use of references check has an inverse relation with the size of a company

The last hypothesis is put forward to determine the most frequently used selection method. Frequency for each method is a subjective number from HR specialist. Respondents are asked to rate the degree of use of selection methods for different levels of vacancies according to the following scale: 5 - always use, 3 - rarely used, 1 - not used.

Several researchers have already identified 3 the most used methods:

- Questionnaire, interview and reference check according to M. Cooke [19]

- Unstructured interviews, reference checks and competency test according to Schneider and Schmitt [4]

- Resume screening, reference checks and structured interview according to British Psychological Society[22]

One can conclude that different researches obtain relatively the same picture. The authors suppose that their research of St. Petersburg companies will show similar result as well. Thus, let us put forward the fifth hypothesis below.

H5: The most frequency used selection methods are screening, interview and references checks

There are several organizational criteria of selection, which influence on the degree of use of selection methods is unpredictable and thus no hypothesis is put forward regarding such criteria. Two such organizational criteria are organizational culture and an HRS coefficient. The HR coefficient is a ratio of the number of employees of the HR Department to the total number of employees of the company. In HRS "S" stands for selection, thus HRS is a ratio of the number of employees of the HR Department who are responsible for selection to the total number of employees of the company.

The hypothesis testing is conducted with regression and correlation methods by testing all sets of criteria (company's business area, the level of difficulty of job position, the size of the company, the age of the company, HRS coefficient and organizational structure) as determinants of the DUSM.

\section{RESEARCH METHODOLOGY}

Dependable variable for the regression model is the degree of use of selection methods (DUSM) described earlier. Factors of the model are choice criteria of selection methods. The 
authors have selected the following criteria from the original list: company's business area, job difficulty, the size of the company, the age of the company, HRS coefficient and organizational structure (Table 1).

TABLE I. CRITERIA DESCRIPTION

\begin{tabular}{|l|l|l|}
\hline \multicolumn{1}{|c|}{ Criterion } & \multicolumn{1}{|c|}{ Factor in the model } & $\begin{array}{c}\text { Method of accounting in } \\
\text { the model }\end{array}$ \\
\hline $\begin{array}{l}\text { Company's } \\
\text { business area }\end{array}$ & $\begin{array}{l}\text { Manufacturing, } \\
\text { Construction, Restaurants } \\
\text { and Hotels, Transport and } \\
\text { Communications, Financial } \\
\text { Sector, Real Estate, } \\
\text { Education, Services }\end{array}$ & $\begin{array}{l}\text { Dummy } \\
\text { business area "Wholesale } \\
\text { and retail trade" is taken } \\
\text { for the base variant }\end{array}$ \\
\hline Job difficulty & The level of seniority & Dummy variable \\
\hline Company's size & Size & Absolute figure \\
\hline Company's age & Age & Absolute figure \\
\hline HRS coefficient & HRS & Absolute figure \\
\hline $\begin{array}{l}\text { Organizational } \\
\text { culture }\end{array}$ & $\begin{array}{l}\text { Hierarchical, Adhocracy, } \\
\text { Clan }\end{array}$ & $\begin{array}{l}\text { Dummy variables, the } \\
\text { market culture is taken } \\
\text { for the base variant }\end{array}$ \\
\hline
\end{tabular}

The sample for this study was formed in two phases. In both cases, the authors had non-random sample because it was hard to form random sample for their purposes. For the first phase of the study, a target sample of 13 companies was used. All companies participated on a voluntary basis. The goal of the first phase was the formation of an optimal questionnaire format to facilitate further data collection process. During this stage, the authors adjust initial set of choice criteria by removing outdated methods and criteria. For the second phase, non-random sample of 40 companies were used, 9 of which were a part of the first sample.

Data collection was carried out in the format of the questionnaire. The first stage took place in the period from 10 to 30 March 2017, the second stage - from March, 22 to May, 19 of 2017.

The authors built a multivariate regression model to determine the direction and the degree of relation between factors and the dependent variable. The model is linear because the authors assume that DUSM is a linear function of all choice criteria. Mathematically, this dependence is generally represented by equation:

$$
y=\beta_{0}+\beta_{1} x_{1}+\cdots+\beta_{n} x_{n}+\varepsilon,
$$

where $\mathrm{y}-$ dependent variable (DUST), $\mathrm{x}$ - factor (choice criterion), $\mathrm{n}$ - number of factors, $\varepsilon \varepsilon-$ const.

it is necessary to describe how some factors are represented in the model. A binary system was used to quantify the factors. However, in case of binary factors, it is necessary to have a base factor. For example, for company's business area, such base factor was "Wholesale and retail trade"; for organizational culture "Market culture" was taken as a base factor; for required entry training 1 month was a base factor. It is important to know what factors are the base ones in order to interpret the model results correctly.

Linear regression models were built in STATA 12.

\section{RESEARCH RESULTS}

The results of the general linear regression model is presented in the table below.

TABLE II. THE RESULTS OF LINEAR REGRESSION FOR DUSM

\begin{tabular}{|c|c|c|c|}
\hline $\begin{array}{l}\text { F-statistics } \\
\text { R-square } \\
\text { adjusted }\end{array}$ & $\begin{array}{l}5.22 \\
0.4018\end{array}$ & & \\
\hline DUSM & $\begin{array}{l}\text { Direction of } \\
\text { relationship }\end{array}$ & P-value & Factor significance \\
\hline Job seniority level & + & 0.000 & Significant \\
\hline Manufacturing & + & 0.023 & Significant \\
\hline Construction & - & 0.495 & Not significant \\
\hline $\begin{array}{l}\text { Restaurants and } \\
\text { hotels }\end{array}$ & - & 0.414 & Not significant \\
\hline $\begin{array}{l}\text { Transport and } \\
\text { communications }\end{array}$ & + & 0.467 & Not significant \\
\hline Financial sector & + & 0.001 & Significant \\
\hline Real estate & + & 0.929 & Not significant \\
\hline Education & - & 0.941 & Not significant \\
\hline Services & + & 0.684 & Not significant \\
\hline Size & + & 0.612 & Not significant \\
\hline Age & - & 0.833 & Not significant \\
\hline HRS & - & 0.002 & Not significant \\
\hline Hierarchical & + & 0.000 & Significant \\
\hline Adhocracy & + & 0.008 & Significant \\
\hline Clan & + & 0.066 & Not significant \\
\hline Days & + & 0.405 & Not significant \\
\hline Weeks & - & 0.852 & Not significant \\
\hline Months & - & 0.521 & Not significant \\
\hline const & + & 0.858 & Not significant \\
\hline
\end{tabular}

The multivariate regression model can be susceptible to the problem of multicollinearity (high correlation between regressors). Table III demonstrates the absence of significant multicollinearity in the model, because the critical values are below 4, while in some researches multicollinearity was rejected even if critical values were less than 8 or even 10 [23], [24].

TABLE III. VARIANCE INFLUENTIAL FACTORS OF REGRESSORS

\begin{tabular}{|l|l|l|}
\hline \multicolumn{1}{|c|}{ Variable } & \multicolumn{1}{|c|}{ VIF } & \multicolumn{1}{c|}{ I/VIF } \\
\hline Size & 2.79 & 0.36 \\
\hline Clan & 2.42 & 0.41 \\
\hline Age & 2.20 & 0.46 \\
\hline Months & 2.13 & 0.47 \\
\hline HRSCoef & 2.08 & 0.48 \\
\hline Weeks & 1.93 & 0.52 \\
\hline Lvl & 1.78 & 0.56 \\
\hline
\end{tabular}




\begin{tabular}{|l|l|l|}
\hline Construction & 1.61 & 0.62 \\
\hline Estate & 1.59 & 0.63 \\
\hline Hierarchical & 1.56 & 0.64 \\
\hline Adhocracy & 1.55 & 0.64 \\
\hline Finance & 1.48 & 0.68 \\
\hline Days & 1.37 & 0.73 \\
\hline Services & 1.32 & 0.76 \\
\hline Transport & 1.23 & 0.81 \\
\hline Education & 1.18 & 0.85 \\
\hline Production & 1.17 & 0.85 \\
\hline Rest & 1.16 & 0.86 \\
\hline Mean VIF & 1.70 & \\
\hline
\end{tabular}

The first hypothesis (H1) about influence of the number of required skills for a position (job seniority level) on the degree of use of selection methods is not statistically rejected with the 95\% confidence interval: regressor "Job seniority level" (see Table II) is significant and has direct relation with dependent variable DUSM.

The second hypothesis (H2) about the inverse relation between DUSM and the required amount of input trainings is tested using the same regression model as for the first hypothesis. Dummy variables of different training periods (days, weeks and months) are insignificant (Table II), thus, the second hypothesis is rejected.

The third hypothesis (H3) about the interdependence of DUSM and company's business area is valid only for Manufacturing and Financial sector (Table II). Given that the base business area in the model was "Wholesale and retail trade", one can interpret the results as follows: the degree of use of selection methods is higher for Manufacturing and Financial sector in comparison with Wholesale and retail trade. Authors believe that it is useful to look at correlation tables (pair correlations between selection methods and business areas) for a more accurate testing of the $\mathrm{H} 3$.

TABLE IV. ALL SIGNIFICANT PAIR CORRELATIONS BETWEEN REGRESSION MODEL FACTORS SELECTION METHODS AND BUSINESS AREAS

\begin{tabular}{|l|c|c|c|}
\hline & $\begin{array}{c}\text { Financial } \\
\text { sector }\end{array}$ & Construction & Manufacturing \\
\hline $\begin{array}{l}\text { Competency } \\
\text { test }\end{array}$ & 0.3609 & - & - \\
\hline $\begin{array}{l}\text { Personality } \\
\text { test }\end{array}$ & 0.4713 & - & - \\
\hline Questionnaire & 0.3954 & - & - \\
\hline Lie detector & 0.7613 & - & - \\
\hline $\begin{array}{l}\text { Telephone } \\
\text { interview }\end{array}$ & - & 0.3187 & 0.4156 \\
\hline $\begin{array}{l}\text { Biographical } \\
\text { method }\end{array}$ & - & - & 0.372 \\
\hline $\begin{array}{l}\text { References } \\
\text { checks }\end{array}$ & - & - & \\
\hline
\end{tabular}

In our subjective opinion, the third hypothesis may be considered valid only for Construction and telephone interview, Manufacturing and both biographical method and reference checks, Financial sector and lie detector.

The factor of size in the regression model (Table II) is not statistically significant, thus let us reject the forth hypothesis about the interdependence between DUSM and the size of the company $\left(\mathrm{H}_{4}\right)$.

However, according to partial correlation matrices, $\mathrm{H}_{4}$ is valid for some methods of selection: personality test, questionnaire, lie detector and telephone interview (see table below).

TABLE V. ALL SIGNIFICANT PAIR CORRELATIONS BETWEEN REGRESSION MODEL FACTORS SELECTION METHODS AND COMPANY'S SIZE

\begin{tabular}{|l|l|}
\hline \multicolumn{1}{|c|}{ Factors } & Size \\
\hline Interview & -0.0234 \\
\hline Competency-based interview & 0.0224 \\
\hline Proficiency test & 0.1562 \\
\hline Competency test & 0.1964 \\
\hline Personality test & 0.482 \\
\hline Questionnaire & 0.3955 \\
\hline Screening & -0.0284 \\
\hline Lie detector & 0.351 \\
\hline Telephone interview & 0.2957 \\
\hline Biographical method & -0.1212 \\
\hline References checks & 0.0889 \\
\hline Assessment center & 0.0974 \\
\hline
\end{tabular}

$\mathrm{H} 4$ is rejected (Table II), individual hypotheses $\mathrm{H} 4 \mathrm{a}$ and $\mathrm{H} 4 \mathrm{~b}$ are rejected as no direct relation between size and the degree of use of any type of interview and inverse relation between size and reference checks are not detected (Table V).

In order to test the fifth hypothesis (H5), whether screening, interview or references checks are the most frequently used selection methods, one does not need to build the regression model. Instead, statistical description is enough. The frequency of methods use was estimated by HR specialists with a 5-point scale, where 5 means very frequently used, 1 - almost never used; then the average number for each selection method was calculated.

According to graph below, H5 is not rejected: let us accept that interview (all kinds), screening and references checks as the most frequently used methods (Fig. 1 below). 


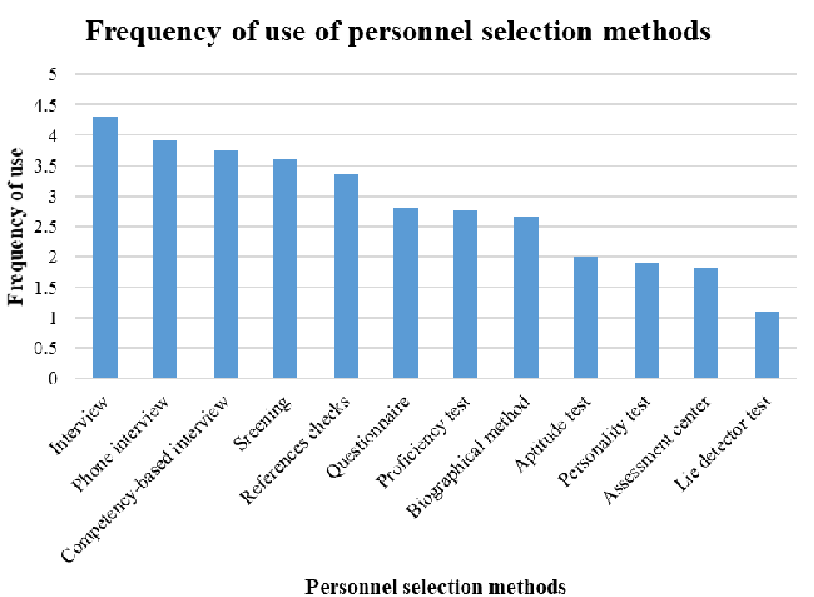

Fig. 2. Frequency of use of personnel selection methods.

So, with the help of statistical methods, the authors have tested 5 hypotheses. $\mathrm{H} 1$ and $\mathrm{H} 5$ were confirmed. $\mathrm{H} 2$ and $\mathrm{H} 4$ were rejected, while $\mathrm{H} 3$ was partially confirmed.

\section{RESULTS INTERPRETATION}

First, the authors would like to stress the limitations of the empirical research - limited sample of 40 companies. Further research with a bigger sample is needed for results validation. Another complicating factor in the analysis of the empirical results is the large number of averaged estimates, mainly relating to the dependent variable, the degree of use of selection methods (DUSM). In particular, average time spent on each selection methods is meant - these raw data obtained from HR specialists can be inaccurate.

The confirmation of the first hypothesis means that the more the skills a job position requires, the greater the degree of use of personnel selection methods. This seems to be sensible assuming that the indicator of job complexity, or a number of required skills, is a job seniority. For all cases, when the total number of required skills increases with the seniority level of the position, the hypothesis stays valid.

The rejection of the second hypothesis means that the required period of entry training has no inverse relation with the degree of use of selection methods. The main problem in testing this hypothesis is the high number of different factors, which are not included in the model, still influence the length of period of entry training. These factors may not be related to candidate's characteristics, which are checked by selection methods. The ideal situation to test this hypothesis would be the presence of mandatory corporate training for all new employees. Unfortunately, such corporate training was not the focus of this study. In the study, there is the prototype of research; this hypothesis was also not confirmed.

The third hypothesis about influence of company's business area on the degree of use of selection methods was rejected in general but partially confirmed for several business areas and methods. In particular, companies from construction sector, on average, use more often and durable telephone interview compared to other companies. Similar results are for manufacturing companies and both biographical methods and reference checks, financial companies and lie detector. Taking into account the minor sample, extrapolating of results on all other companies is not accurate.

The forth hypothesis about relation between company's size and DUSM is partially confirmed for several selection methods. Personality tests have the highest correlation with company's size. This may indicate that big companies have mandatory training and thus more concerned about personal characteristics rather than competencies. Big companies also more often use questionnaire according to results. Probably this is because of greater scale of bureaucracy in large companies. The relation between the use of telephone interviews and the size of the company is surprising, as phone interviews are used in almost all companies for vacancies of all levels. Perhaps the degree of use of phone interview rises in big companies with the increase of time spent on an interview. Probably HR professionals in small companies prefer to spend less time on the phone interview, finding out all necessary information during in-person meetings.

The test results of the fifth hypothesis reflect the pattern of modern selection through the frequency of use of the selection methods. These findings confirm the results of earlier studies. The most popular method is an interview, while a competency-based interview is just slightly behind. Phone interviews, as already noted, are the second most popular method. Among the group of tests, a very low frequency are aptitude tests and personality tests. The assessment center is not one of the most popular, which is natural given the necessary expenses to carry it out.

These are the results interpretation of this empirical analysis. Some of results are of particular value, given that the study is not typical for the field of personnel selection.

\section{References}

[1] D. Greenidge, P. Alleyne, B. Parris, S. Grant, , "A comparative study of recruitment and training practices between small and large businesses in an emerging market economy: The case of Barbados", Journal of Small Business and Enterprise Development, 19(1), pp. 164-182, 2012.

[2] M. Carroll, Marchington, M., Earnshaw, J., Taylor, S., "Recruitment in small firms: Processes, methods and problems", Employee relations, 21(3), pp. 236-250, 1999.

[3] C. Tanova, "Firm size and recruitment: staffing practices in small and large organisations in north Cyprus", Career Development International, 8(2), pp. 107-114, 2003.

[4] B. Schneider, D. B. Smith, Personality and organizations. Psychology Press, 2004, pp. 151-168.

[5] D. Cooper, I. T. Robertson, G. Tinline, Recruitment and selection: A framework for success, Cengage Learning EMEA, 2003, pp. 109-118.

[6] Wilk, S. L., Cappelli, P., "Understanding the determinants of employer use of selection methods", Personnel Psychology, 56(1), pp. 103-124, 2003.

[7] R. E. Miles, C. C.Snow, "Designing strategic human resources systems", Organizational dynamics, 13(1), pp. 36-52, 1984.

[8] L. C. Christiansen, M. Higgs, "How the alignment of business strategy and HR strategy can impact performance: A practical insight for managers", Journal of General Management, 33(4), pp. 13-34, 2008.

[9] E. Parry, Wilson, "Factors influencing the adoption of online recruitment", Personnel Review, 38(6), pp. 655-673, 2009. 
[10] J. W. Boudreau, "Decision theory contributions to HRM research and practice", Industrial Relations: A Journal of Economy and Society, 23(2), 1984, pp. 198-217.

[11] Roberts, G., Recruitment and Selection: A competency approach, CIPD Publishing, 1997, pp. 69-76.

[12] Ivanova S., The art of personnel selection: how to evaluate a candidate for one hour. Moscow. 2d ed. Alpina Business Book, 2005, pp. 78-84.

[13] R. E. Boyatzis, The competent manager: A model for effective performance. John Wiley \& Sons, 1982, pp. 326-333.

[14] S. Whiddett, S. Hollyforde, A practical guide to competencies: how to enhance individual and organisational performance, CIPD Publishing, 2003, pp. 135-141.

[15] A. Denisov, M. Latukha, "The use of interactive technologies in personnel selection process", Vestnik (Herald) of Saint Petersburg University. Psychology. Sociology. Pedagogy, pp. 200-212, 2009.

[16] A. Y. Kibanov, D. K. Zakharov, Organization of personnel management in the enterprise, 2006, pp. 213-214.

[17] Studying while working//web-site Head Hunter. Questionnaire of 189 companies. http://spb.hh.ru/article/14634?utm_content=soisk_iss12_100 214\&utm_medium=email\&utm_campaign $=$ misc\&utm_source $=$ email

[18] A. N. N. Ryan, L. McFarland, H. B. SHL, "An international look at selection practices: Nation and culture as explanations for variability in practice", Personnel Psychology, 52(2), pp. 359-392, 1999.
[19] M. Armstrong, The practice of human resource management. Trans. from English. 8th ed. SPb.: Peter, 2004, pp. 263-267.

[20] F. Dany, V. Torchy, "Recruitment and selection in Europe: policies, practices and methods", Policy and practice in European human resource management: The price water house cranfield survey, pp. 68-88, 1994.

[21] G. P. Hodgkinson, R. L. Payne, "Graduate selection in three European countries", Journal of Occupational and Organizational psychology, 71(4), pp. 359-365, 1998.

[22] L. D. Zibarras, S. A. Woods, "A survey of UK selection practices across different organization sizes and industry sectors", Journal of Occupational and Organizational Psychology, 83(2), pp. 499-511, 2010.

[23] I.V. Berezinets, Basics of econometrics, Graduate School of Management, 2011, pp. 114-116.

[24] D. A. Belsley, E. Kuh, R. E. Welsch, Regression diagnostics: Identifying influential data and sources of collinearity, John Wiley \& Sons, Vol. 571, 2005., pp. 221-224.

[25] M. Cook, ersonnel selection: adding value through people - a changing picture, John Wiley \& Sons, 2016., pp. 414-419. 